\title{
Dragonfly Mercury Project-A Citizen Science Driven Approach to Linking Surface-Water Chemistry and Landscape Characteristics to Biosentinels on a National Scale
}

Mercury is a globally distributed pollutant that threatens human and ecosystem health. Even protected areas, such as national parks, are subjected to mercury contamination because it is delivered through atmospheric deposition, often after long-range transport. In aquatic ecosystems, certain environmental conditions can promote microbial processes that convert inorganic mercury to an organic form (methylmercury). Methylmercury biomagnifies through food webs and is a potent neurotoxicant and endocrine disruptor. The U.S. Geological Survey (USGS), the University of Maine, and the National Park Service (NPS) Air Resources Division are working in partnership at more than 50 national parks across the United States, and with citizen scientists as key participants in data collection, to develop dragonfly nymphs as biosentinels for mercury in aquatic food webs. To validate the use of these biosentinels, and gain a better understanding of the connection between biotic and abiotic pools of mercury, this project also includes collection of landscape data and surface-water chemistry including mercury, methylmercury, $\mathrm{pH}$, sulfate, and dissolved organic carbon and sediment mercury concentration. Because of the wide geographic scope of the research, the project also provides a nationwide "snapshot" of mercury in primarily undeveloped watersheds (fig. 1).

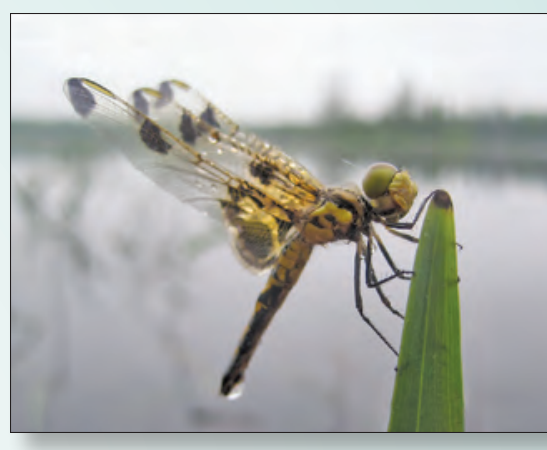

Dragonflies spend their larval stages in aquatic habitats, and then molt and emerge as terrestrial adults. They are an important connection between aquatic and terrestrial environments. (Photograph by Sarah Nelson, University of Maine.)

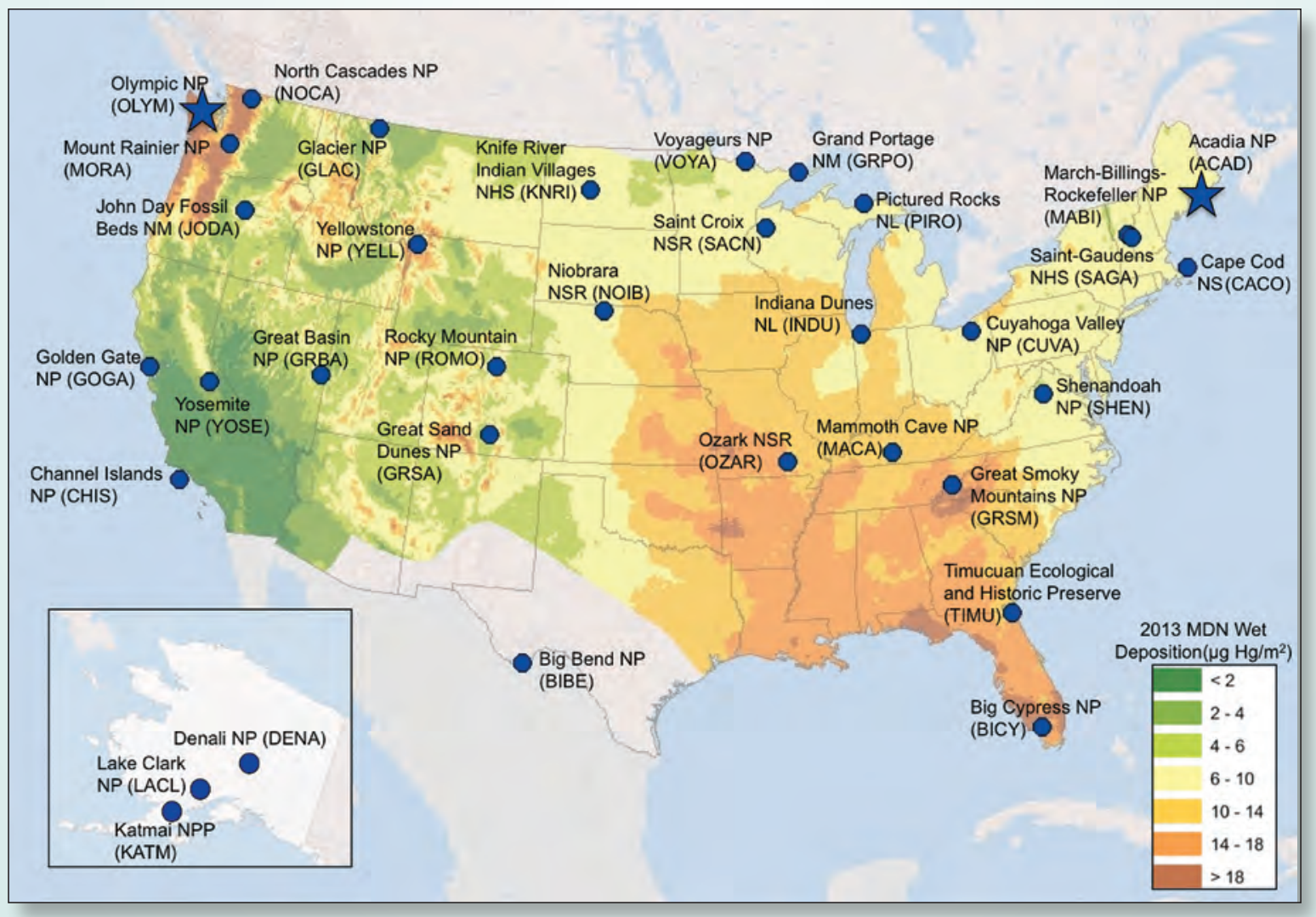

Figure 1. Map showing 34 national parks sampled as part of the Dragonfly Mercury Project during 2014. The project expanded from 12 national parks participating in a pilot effort in 2012 to more than 50 national parks participating in 2015. Olympic and Acadia National Parks, denoted with a star, were sampled more frequently (4 times per year) and with greater spatial coverage (more than 10 sites) than the other national parks. Estimates of mercury wet deposition from 2013 are provided by the National Atmospheric Deposition Program, Mercury Deposition Network (http://nadp.sws.uiuc.edu/mdn/). 


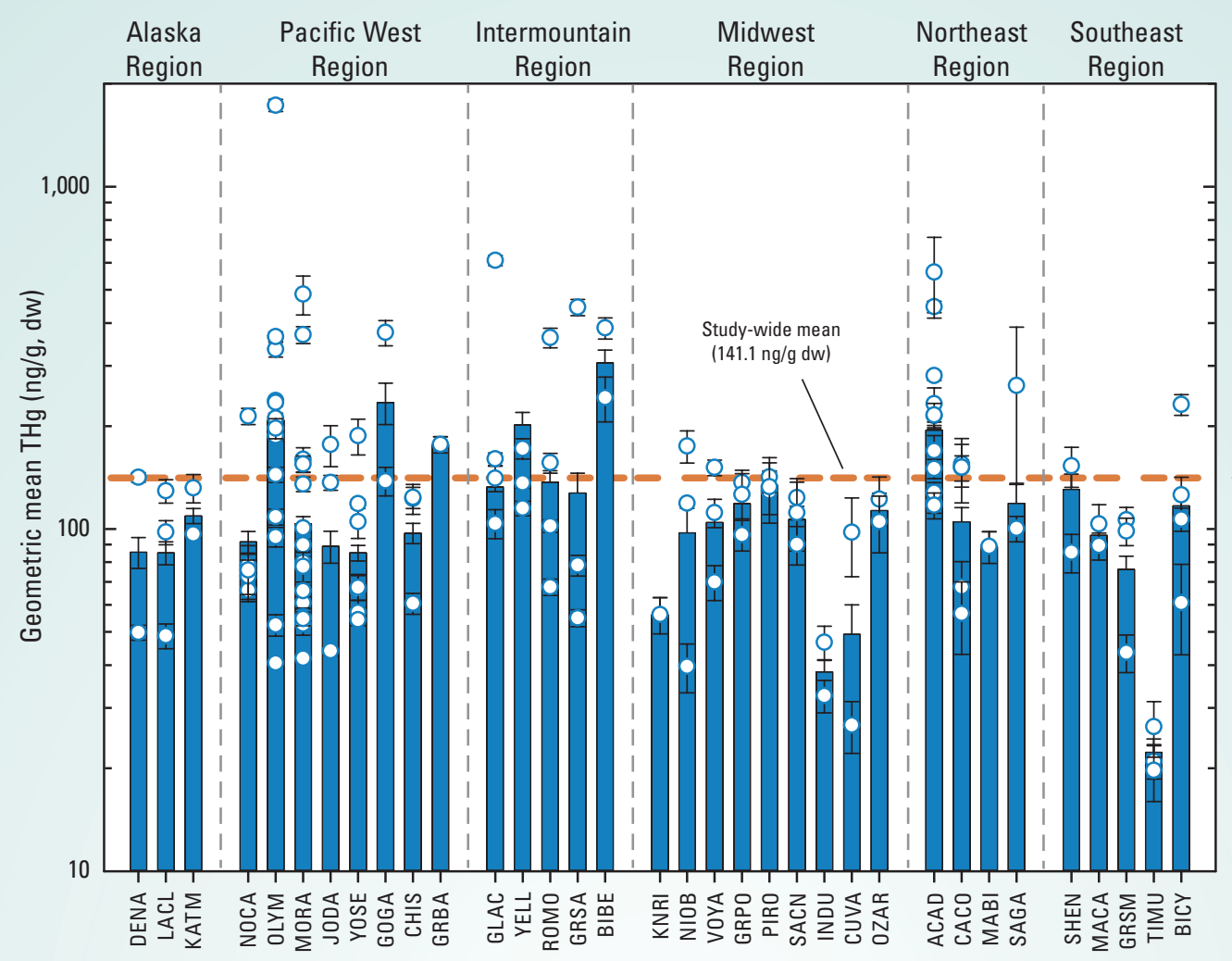

Figure 3. Geometric mean of dragonfly larvae total mercury $(\mathrm{THg})$ concentrations by national park (bars) and by site within national parks (dots), 2014. Error bars represent standard error. Note the data are displayed on a log scale. Values are in nanograms per gram dry weight $(\mathrm{ng} / \mathrm{g}, \mathrm{dw})$. See figure 1 for park abbreviations.

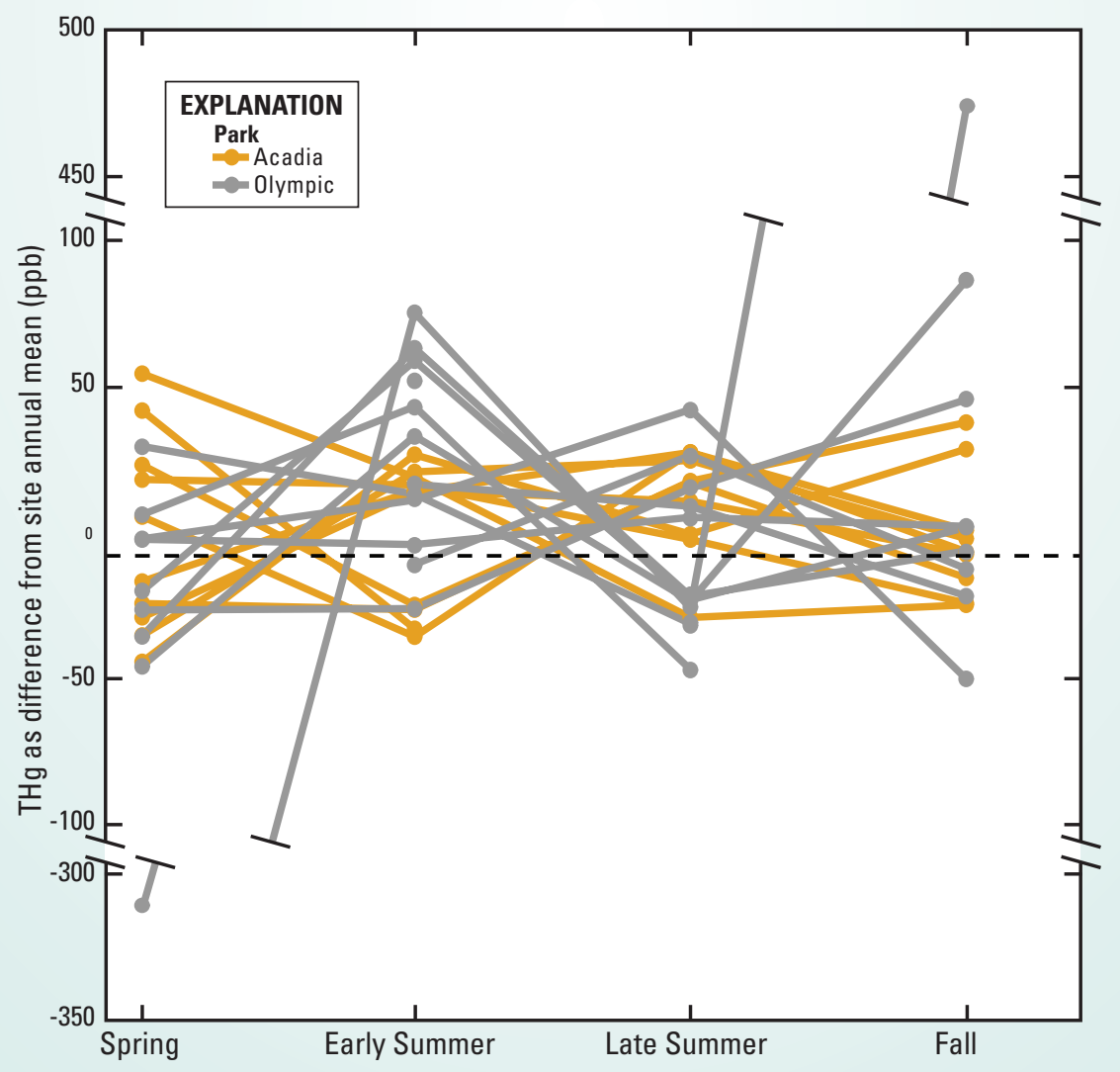

Figure 4. Example data of relative seasonal concentrations of total mercury ( $\mathrm{THg}$ ) in dragonfly larvae represented as the difference from the site-specific annual mean in parts per billion (ppb), Acadia and Olympic National Parks, 2014. 
